\title{
CARACTERÍSTICAS DE SOLOS SISTEMATIZADOS EM DUAS ÁREAS CULTIVADAS COM ARROZ SOB INUNDAÇÃO(1)
}

\author{
M. L. NUNE $S^{(2)}, E . K_{L A M T}^{(3)}$, \\ J. M. REICHERT ${ }^{(4)} \&$ R.S. D. DALMOLIN ${ }^{(5)}$
}

\begin{abstract}
RESUMO
A sistematização dos solos, um processo de adequação da superfície do terreno, vem sendo introduzida em grande escala em diversas propriedades orizícolas do estado do Rio Grande do Sul, gerando alterações nas propriedades morfológicas, físicas, químicas e biológicas dos solos. Para estudar estas alterações, selecionaram-se áreas-testes em superfícies homogêneas onde ocorrem Planossolos sistematizados em diferentes épocas (oito anos, um ano e um mês) e em perfis não alterados (original), no município de SãoJ oão do Polêsine (RS). A descrição morfológica e a coleta de amostras dos horizontes e, ou, camadas dos perfis representativos das áreas de corte e aterro (sistematizadas) e não alterados foram efetuadas em 1997/98. Nas áreas de corte, observaram-se as maiores alterações em relação aos perfis originais, com concentração mais elevada de argila, teores mais baixos de carbono orgânico e fósforo e teor mais elevado de Al trocável, principalmente no primeiro ano após a sistematização. A sistematização aumentou a densidade do solo em subsuperfície, em razão do intenso tráfego de máquinas, e reduziu a compactação na superfície, pelo revolvimento com o preparo do solo e incorporação de resíduos da cultura do arroz. As camadas superficiais dos perfis de corte apresentaram teores de $F$ et, Fed e Alt semelhantes aos do horizonte Btg do perfil original. Os ciclos de umedecimento e secagem a que os solos foram submetidos alteraram os tipos de óxidos de ferro, com aumento das formas mal cristalizadas.
\end{abstract}

Termos de indexação: sistematização do solo, morfologia do solo, óxidos de ferro.

\footnotetext{
(1) Parte da Tese de Mestrado, apresentada pelo primeiro autor ao Programa de Pós-Graduação em Agronomia da Universidade Federal de Santa Maria - UFSM. Recebido para publicação em jul ho de 2000 e aprovado em outubro de 2001.

(2) Engenheiro-Agronômo, MSc, Rua J oão Pessoa, 773/303, CEP 96010-470 Pel otas (RS). E-mail: mnunes@geo.uapt

(3) Professor Titular A posentado, Departamento de Solos, Universidade Federal do Rio Grande do Sul - UFRGS. Caixa Postal 776, CEP 90001-970 Porto Alegre (RS). E-mail:fklamt@terra.com.br

(4) Professor Titular, Departamento de Solos, Universidade Federal de Santa Maria - UFSM. CEP 97105-900 Santa Maria (RS). Pesquisador do CNPq. E-mail: reichert@ccr.ufsm.br

(5) Professor Assistente, Departamento de Solos, UFSM. E-mail: dalmolinrsd@bol.com.br
} 


\title{
SUMMARY: SOIL PROPERTIES AFFECTED BY LAND LEVELING AT TWO PADDY RICE FIELDS
}

\begin{abstract}
Soil or land leveling, a process of adequation of land surface, is being practiced in many ricegrowing farms in the state of Rio Grande do Sul, Brazil. This process produces profound changes in themorphol ogical, physical, chemical, and biological properties of the soil. To study these changes, test areas were selected with homogeneous surfaces where Planosols occur and on which land leveling was performed for eight years, one year, and onemonth and with original soil, at SãoJ oão do Polêsine Soil morphology was described and soil samples coll lected at horizons and/ or soil layers of level ed (cut and filled-in) profiles and original (unleveled soil) areas. In the areas of removal of (cut) material, significant changes wereobserved, name y higher cl ay content, low soil organic carbon and phosphorus, as well as higher exchangeable aluminum, mainly in areas of one year after leveling. The leveling process increased soil bulk density and reduced total porosity in the subsurface, dueto theintensemachinery traffic. The compaction of thesurfacelayer was reduced by soil tillage and incorporation of rice crop residues. Total and DCB extracted iron and total aluminum of the subsurfacelayers of cut profiles weresimilar to the original Btg horizon. Soil wetting and drying cycles, originated by riceirrigation, affected thetypes of iron oxide, increasing oxides with low crystal inity.
\end{abstract}

Index terms: Land leveling, soil morphology, iron oxides.

\section{NTRODUÇÃO}

O processo de sistematização, utilizado por orizicultores gaúchos, consiste no nivelamento da superfície do solo, em um plano pré-definido, utilizando o sol o das cotas mais el evadas (originando áreas de corte) para aterrar os de cotas inferiores (originando áreas de aterro) (IRGA, 1996; EMBRAPA, 1999b). Este processo origina terraços em forma de patamar como os encontrados amplamente na China, J apão e Filipinas. O terreno plano formado apresenta vantagens em relação à superfície original, como um mel hor manejo da água (Anbumozhi et al., 1998), menor incidência de pragas e doenças, menor oscilação de temperatura da água e solo, além de melhorar a eficiência nos tratos culturais. O melhor aproveitamento do solo, devido à redução da área ocupada com tai pas, ea economia de insumos também foram destacados (E MBRAPA, 1992; Parfitt et al., 1999), além da incorporação de áreas para o cultivo dearroz irrigado, não adequadas para tal nas condições originais (Anbumozhi et al., 1998).

Nesse processo, percebe-se grandemobilização de solo, ocorrendo uma mistura de horizontes, originando sol os com estratificação de material nas áreas de aterro e, muitas vezes, a exposição do horizonte subsuperficial nas áreas de corte. As condi ções naturais do sol o são modificadas, afetando várias de suas características, particularmente os compostos de ferro, que são susceptíveis às condições de oxirredução em cultivo de arroz por inundação (Kämpf, 1987). A produtividade de cultivos é reduzida em áreas de exposição da subsuperfície do sol o em razão da baixa concentração de nutrientes e de matéria orgânica (Heilman \& Thomas, 1961; Thomas et al., 1974; Preve \& Martens, 1990; Unger et al., 1990). Estratégias para recuperação química dessas áreas incluem a fertilização inorgânica (Thomas et al., 1974) ou orgânica (Robbins et al., 1997).

Apesar de ser uma prática usual nas áreas orizícolas do estado do Rio Grande do Sul, praticamente inexistem trabal hos publicados sobre sistematização, seus efeitos nas propriedades dos sol os e evol ução dessas propriedades com os cultivos subseqüentes de arroz e outras culturas.

O objetivo principal destetrabalho foi quantificar eavaliar as alterações nas propriedades morfológicas, físicas e químicas de solos sistematizados, dando ênfase às formas dos óxidos de ferro.

\section{MATERIAL E MÉTODOS}

No mapa de solos do município de São J oão do Polêsine na região da Depressão Central do Rio Grande do Sul, na escala 1:20.000 (Klamt et al., 1997), foram selecionadas áreas de ocorrência de Planossolos $\mathrm{Hidromórficos} \mathrm{eutróficos} \mathrm{típicos}$ (EMBRAPA, 1999a) não sistematizados adjacentes a áreas com sistematização do terreno. Com o auxílio dos proprietários destas áreas, avaliaram-se o processo de sistematização utilizado, a data de execução e o tipo de manejo imposto a estas áreas. Após checagem em campo das características dos sol os, sel ecionaram-se duas áreas-testes onde foram descritos e amostrados oito perfis de solos segundo método descrito por Lemos \& Santos (1996). 
Na área 1, foram estudados o perfil original (1PO), perfis de aterro e de corte com um mês (1PA e $\left.1 \mathrm{PC}_{0}\right)$ e com um ano $\left(1 \mathrm{PA}_{1}\right.$ e $\left.1 \mathrm{PC}_{1}\right)$ após a sistematização. Na área 2, os perfis estudados foram: perfil original (2PO) e perfil de aterro e corte com oito anos após a sistematização (2PA $\mathrm{P}_{8}$ e $\left.2 \mathrm{PC}_{8}\right)$.

As áreas 1 e 2 , de aproximadamente 2 ha cada, estão separadas por uma distância aproximada de 500 meapresentam particularidades distintas entre si. A área 1 apresenta, na superfície do solo, exposição de horizonte subsuperficial argiloso, graças à maior profundidade de corte durante o processo de sistematização; enquanto, na área 2, o material é mais arenoso, sendo a profundidade de corte menor.

As descrições e as amostragens dos perfis $1 \mathrm{PA}_{0} \mathrm{e}$ $1 P C_{0}$ foram feitas em solo sem qual quer vegetaçãoe adubação, enquanto, nos perfis $1 \mathrm{PA}_{1}, 1 \mathrm{PC}_{1}, 2 \mathrm{PA}_{8} \mathrm{e}$ $2 \mathrm{PC}_{8}$, o sol o estava com plantas de arroz emergidas há 30 dias eadubado com NPK na semeadura.

As amostras, após secas ao ar, foram destor roadas e peneiradas, obtendo-se a fração com diâmetro menor que $2 \mathrm{~mm}$ (TFSA). As análises físicas determinaram a composição granulométrica com quantificação da areia por peneiramento úmido, argila pel o método de B oyoucos e silte por diferença (EMBRAPA, 1997); a densidade do solo, a partir de amostras indeformadas coletadas com anel vol umétrico de Köpeck, e a densidade de partículas, pel o método do pi cnômetro (Blake \& Hartge, 1986). A porosidade total (Pt) foi calculada com base nas densidades do solo (ds) e de partículas (dp) pela equação: Pt $\left(\mathrm{dm}^{3} \mathrm{dm}^{-3}\right)=(\mathrm{dp}-\mathrm{ds}) / \mathrm{dp}$.

As análises químicas determinadas foram: $\mathrm{pH}$ em água e em KCl $1 \mathrm{~mol} \mathrm{~L}^{-1}$, medidos com el etrodo de vidro em suspensão sol o-água ou solo-sol ução de $\mathrm{KCl}$ $1 \mathrm{~mol} \mathrm{~L}^{-1}$ na proporção solo-líquido 1:2,5; carbono orgânico, pela oxidação via úmida com $\mathrm{K}_{2} \mathrm{Cr}_{2} \mathrm{O}_{4} \mathrm{e}$ titulação com $\mathrm{FeSO}_{4} 0,05 \mathrm{~mol} \mathrm{~L}^{-1}$; Al trocável, extraído com solução de $\mathrm{KCl} 1 \mathrm{~mol} \mathrm{~L}^{-1}$ e quantificado por titulometria com $\mathrm{NaOH}$ 0,025 mol L-1 e azulbromitimol com indicador; $\mathrm{H}+\mathrm{Al}$, extraídos com solução de $\mathrm{Ca}(\mathrm{OAC})_{2}$ 0,5 mol L-1 $\mathrm{pH}$ 7,0 e titulados com $\mathrm{NaOH}$ 0,0606 mol L-1 e fenolftaleína como indicador; $\mathrm{H}$, calculado por diferença (EMBRAPA, 1997); $\mathrm{Ca}^{2+}$ e $\mathrm{Mg}^{2+}$, extraídos com solução de $\mathrm{KCl}$ $1 \mathrm{~mol} \mathrm{L^{-1 }}$ e determinados por espectrofotometria de absorção atômica; $\mathrm{K}^{+}$e $\mathrm{Na}^{+}$, extraídos com solução $\mathrm{PA}\left(\mathrm{HCl} 0,05 \mathrm{~mol} \mathrm{~L}^{-1}+\mathrm{H}_{2} \mathrm{SO}_{4} 0,0125 \mathrm{~mol} \mathrm{~L}^{-1}\right.$ ) e determinados por fotometria de chama; fósforo extraível, obtido com sol ução de PA $\left(\mathrm{HCl} 0,05 \mathrm{~mol} \mathrm{~L}^{-1}+\mathrm{H}_{2} \mathrm{SO}_{4}\right.$ $\left.0,0125 \mathrm{~mol} \mathrm{~L}^{-1}\right)$ mais solução dePB $\left(\mathrm{HCl} 0,87 \mathrm{~mol} \mathrm{~L}^{-1}\right.$ e $\left(\mathrm{NH}_{4}\right)_{6} \mathrm{Mo}_{7} \mathrm{O}_{24} \cdot 4 \mathrm{H}_{2} \mathrm{O}$ ) ePC (ácido 1-amino-2-naftol4-sulfônico, sulfito de sódio e metabissulfito de sódio) e determinado por col orimetria (Tedesco et al., 1995).

A soma de bases (S), saturação por bases $(V)$ e por alumínio e a capacidade de troca de cátions (CTC) foram cal culadas segundo E MBRAPA (1997), e a atividade da argila foi estimada segundo Camargo et al. (1987).
Os teores deFeeAl totais (Fet eAlt) foram determinados por digestão em $\mathrm{HCl} 6 \mathrm{~mol} \mathrm{~L}-1$ (Dick \& Kämpf, 1988); FeeAl na forma de oxihidróxidos "livres" (Fed e Ald) foram extraídos com ditionito-citratobicarbonato (DCB) (Mehra \& J ackson, 1960), enquanto Fe e Al de baixa cristalinidade (Feo e Alo) foram extraídos com oxalato de amônio (Mckeague \& Day, 1966). A determinação desses el ementos em cada um dos extratos foi efetuada por espectrofotometria de absorção atômica.

As al terações nos sol os impostas pela sistematização do terreno foram avaliadas comparando as propriedades dos perfis originais aos perfis afetados pel o processo.

\section{RESULTADOS E DISCUSSÃO}

\section{Morfologia dos solos}

As características morfológicas dos perfis encontram-se no quadro 1 . Em relação aos respectivos perfis originais $1 \mathrm{PO}$ e $2 \mathrm{PO}$, os perfis de corte $1 \mathrm{PC}_{0}, 1 \mathrm{PC}_{1}$ e $2 \mathrm{PC}_{8}$ diferenciaram-se por apresentar exposição de material da subsuperfície (horizontes Btge, ou, EB) na superfíciesistematizada do solo, evidenciados pela semelhança na cor, teor de argila e consistência do sol o. Essas características constituem um dos principais problemas em solos sistematizados recentemente, implicando prováveis limitações às práticas de manejo.

Os perfis de aterro $1 P A_{0}, 1 P A_{1}$ e $2 \mathrm{PA}_{8}$ diferiram dos originais quanto à cor da matriz, com presença de mosqueados, e estrutura moderada e laminar. A presença de estrutura laminar, nos primeiros $20 \mathrm{~cm}$ de profundidade, deveu-se à compressão do solo exercida pelo tráfego de equipamentos pesados no processo de sistematização e manejo do solo (Machado et al., 1981) onde alterações na estabilidade de agregados eram esperadas (Unger et al., 1990). Assim, a presença de camadas estratificadas, originadas da sobreposição de materiais heterogêneos, ea exposição de horizontes subsuperficiais na superfície dos solos, originados pela remoção dos horizontes superficiais, foram causas das variações das características morfológicas dos solos sistematizados. Dessa forma, as características morfológicas desses solos foram dependentes do tipo de solo utilizado e do processo de sistematização, aos quais se sobrepõem os processos pedogênicos, como descrito por Kämpf et al. (1997).

\section{Propriedades físicas}

Os perfis originais apresentaram gradiente textural abrupto entre os horizontes E ou EB eBtg, característica de Planossolo (Quadro 2). Em relação ao respectivo perfil original (1PO), os perfis de aterro 
Quadro 1. Características morfológicas de diferentes horizontes e, ou, camadas, de perfis originais e solos sistematizados (corte e aterro) para o cultivo de arroz

\begin{tabular}{|c|c|c|c|c|c|c|c|}
\hline \multirow{2}{*}{$\begin{array}{l}\text { Horizonte } \\
\text { e, ou, } \\
\text { camada }\end{array}$} & \multirow{2}{*}{ Limite } & \multirow{2}{*}{$\begin{array}{l}\text { Cor solo } \\
\text { úmido }\end{array}$} & \multirow{2}{*}{ Textura(1) } & \multirow{2}{*}{ Estrutura } & \multicolumn{3}{|c|}{ Consistência(2) } \\
\hline & & & & & Seca & Úmida & Molhada \\
\hline \multicolumn{8}{|c|}{$\begin{array}{c}\text { Área 1 } \\
\text { Perfil original - 1PO }\end{array}$} \\
\hline $\begin{array}{l}\mathrm{A}_{1} \\
\mathrm{E} \\
\mathrm{Btg}\end{array}$ & $\begin{array}{l}0-40 \\
40-80 \\
70-130+\end{array}$ & $\begin{array}{l}10 Y R 4,5 / 2 \\
10 Y R 5 / 1,5 \\
10 Y R 4 / 1\end{array}$ & $\begin{array}{l}\text { FA } \\
\text { FA } \\
\text { MA }\end{array}$ & $\begin{array}{l}\text { Fraca, blocos subangulares } \\
\text { Fraca, blocos subangulares, maciça } \\
\text { Moderada, prismática e col unar }\end{array}$ & $\begin{array}{l}\text { LD } \\
\text { MD } \\
E D\end{array}$ & $\begin{array}{l}\mathrm{Fr} \\
\mathrm{MF} \\
\mathrm{F}\end{array}$ & $\begin{array}{l}N P / L P \\
N P / L P \\
P / P\end{array}$ \\
\hline \multicolumn{8}{|c|}{ Perfil de aterro - 1PA0 } \\
\hline $\begin{array}{l}I \\
I 1 \\
A_{1} b \\
B E b \\
\text { Btgfb }\end{array}$ & $\begin{array}{l}0-10 \\
10-19 / 21 \\
19 / 21-27 / 35 \\
27 / 35-58 / 64 \\
58 / 64-110+\end{array}$ & $\begin{array}{l}10 Y R 3 / 2,5 \\
10 Y R 3 / 2 \\
10 Y R 3,5 / 1 \\
10 Y R 4,5 / 2 \\
10 Y R 4 / 1\end{array}$ & $\begin{array}{l}\text { FAA } \\
\text { FAA } \\
\text { FAA } \\
\text { FAA } \\
\text { MA }\end{array}$ & $\begin{array}{l}--(3) \\
-- \\
-- \\
-- \\
--\end{array}$ & $\begin{array}{l}\text { MD } \\
M D \\
M D \\
-- \\
E D\end{array}$ & $\begin{array}{l}-- \\
-- \\
-- \\
-- \\
--\end{array}$ & $\begin{array}{l}\text { LP/LP } \\
\text { LP/LP } \\
P / L P \\
\text { LP/LP } \\
P / P\end{array}$ \\
\hline \multicolumn{8}{|c|}{ Perfil de aterro - 1PA } \\
\hline $\begin{array}{l}\text { I } \\
\text { Ab } \\
\text { E/Ebb } \\
\text { Btgfb }\end{array}$ & $\begin{array}{l}0-20 \\
20-31 \\
31-62 \\
62-80+\end{array}$ & $\begin{array}{l}7,5 Y R 3 / 2 \\
10 Y R 3 / 1 \\
7,5 Y R 5 / 2 \\
10 Y R 4 / 1\end{array}$ & $\begin{array}{l}\text { FAA } \\
\text { F } \\
\text { FA } \\
\text { A }\end{array}$ & $\begin{array}{l}\text { Moderada, laminar } \\
\text { Moderada, bl ocos subangulares } \\
\text { Moderada, blocos subangulares } \\
\text { Maciça, blocos subangulares }\end{array}$ & $\begin{array}{l}\text { MD } \\
\text { MD } \\
\text { LD } \\
\text { MD }\end{array}$ & $\begin{array}{l}\mathrm{Fr} / \mathrm{F} \\
\mathrm{Fr} / \mathrm{F} \\
\mathrm{Fr} \\
\mathrm{MF}\end{array}$ & $\begin{array}{l}\text { LP/LP } \\
\text { LP/LP } \\
\text { LP/LP } \\
M P / P\end{array}$ \\
\hline \multicolumn{8}{|c|}{ Perfil de corte - 1PC 0} \\
\hline $\begin{array}{l}\text { I (Btg) } \\
\text { II }\end{array}$ & $\begin{array}{r}0-20 \\
20-40 \\
40-60\end{array}$ & $\begin{array}{l}\text { 10YR } 4 / 1 \\
10 Y R 4 / 1 \\
10 Y R 4 / 1\end{array}$ & $\begin{array}{l}M A \\
A\end{array}$ & $\begin{array}{l}-- \\
-- \\
--\end{array}$ & $\begin{array}{l}E D \\
E D \\
M D\end{array}$ & $\begin{array}{l}-- \\
-- \\
--\end{array}$ & $\begin{array}{l}-(1) \\
P / P \\
P / P\end{array}$ \\
\hline \multicolumn{8}{|c|}{ Perfil de corte - $1 \mathrm{PC}_{1}$} \\
\hline $\begin{array}{l}\text { Ap } \\
\text { I(Btg) } \\
\text { II } \\
\text { III }\end{array}$ & $\begin{array}{l}0-5 / 7 \\
5 / 7-20 \\
20-40 \\
40-60\end{array}$ & $\begin{array}{l}10 Y R 4,5 / 3 \\
10 Y R 4 / 1 \\
10 Y R 4 / 1 \\
10 Y R 4 / 1\end{array}$ & $\begin{array}{l}\text { FA } \\
\text { MA } \\
\text { MA } \\
\text { A }\end{array}$ & $\begin{array}{l}\text { Fraca, blocos subangulares } \\
\text { Moderada, bl ocos subangulares } \\
\text { Moderada, blocos e subangulares } \\
\text { Moderada, blocos e subangulares }\end{array}$ & $\begin{array}{l}\text { LD } \\
\text { ED } \\
\text { ED } \\
\text { MD }\end{array}$ & $\begin{array}{l}\mathrm{MFr} \\
\mathrm{F} / \mathrm{MF} \\
\mathrm{MF}\end{array}$ & $\begin{array}{l}L P / L P \\
M P / M P \\
M P / M P \\
P / P\end{array}$ \\
\hline \multicolumn{8}{|c|}{$\begin{array}{c}\text { Área } 2 \\
\text { Perfil original - 2PO }\end{array}$} \\
\hline $\begin{array}{l}A^{1} \\
E \\
E B \\
\text { Btg }\end{array}$ & $\begin{array}{l}\quad 0-25 \\
25-33 / 45 \\
33 / 45-70 / 74 \\
70-125\end{array}$ & $\begin{array}{l}7,5 Y R 3 / 2 \\
10 Y R 5 / 2,5 \\
10 Y R 5 / 2 \\
7,5 Y R 3 / 2\end{array}$ & $\begin{array}{l}\text { FAA } \\
\text { AF } \\
\text { FA } \\
\text { A }\end{array}$ & $\begin{array}{l}\text { Moderada, blocos subangulares } \\
\text { F raca, blocos subangulares } \\
\text { Moderada, blocos subangulares } \\
\text { Maciça, blocos prismáticos }\end{array}$ & $\begin{array}{l}\text { LD } \\
\text { LD } \\
\text { LD } \\
\text { ED }\end{array}$ & $\begin{array}{l}\mathrm{Fr} \\
\mathrm{MF} \\
\mathrm{F} \\
\mathrm{F}\end{array}$ & $\begin{array}{l}L P / L P \\
N P / N P \\
L P / L P \\
P / P\end{array}$ \\
\hline \multicolumn{8}{|c|}{ Perfil de aterro - $2 \mathrm{PA}_{8}$} \\
\hline $\begin{array}{l}\text { Ap } \\
\text { II } \\
\text { III } \\
\text { IV }\end{array}$ & $\begin{array}{l}0-22 \\
22-54 \\
54-68 \\
68-100+\end{array}$ & $\begin{array}{l}5 Y R 4 / 3 \\
10 Y R 4 / 3 \\
7,5 Y R 4 / 1 \\
10 Y R 4 / 3\end{array}$ & $\begin{array}{l}\text { FA } \\
\text { AF } \\
\text { F } \\
\text { F }\end{array}$ & $\begin{array}{l}\text { Laminar } \\
\text { Fraca, blocos subangulares } \\
\text { Fraca, colunar } \\
\text { Maciço }\end{array}$ & $\begin{array}{l}\text { LD } \\
\text { LD } \\
\text { ED } \\
\text { ED }\end{array}$ & $\begin{array}{l}\mathrm{Fr} \\
\mathrm{MFr} \\
\mathrm{F} \\
\mathrm{F}\end{array}$ & $\begin{array}{l}\text { LP/LP } \\
N P / N P \\
\text { LP/LP } \\
\text { LP/LP }\end{array}$ \\
\hline \multicolumn{8}{|c|}{ Perfil de corte - $2 \mathrm{PC}_{8}$} \\
\hline $\begin{array}{l}\text { Ap } \\
\text { II(EB) } \\
\text { III(Btg) }\end{array}$ & $\begin{array}{l}0-13 \\
11 / 13-20 \\
20-60\end{array}$ & $\begin{array}{l}7,5 Y R 4 / 4 \\
10 Y R 4 / 3 \\
5 Y R 4 / 1\end{array}$ & $\begin{array}{l}\text { F } \\
\text { FAA } \\
\text { A }\end{array}$ & $\begin{array}{l}\text { Moderada a forte, laminar } \\
\text { Maciça } \\
\text { Moderada, blocos prismáticos }\end{array}$ & $\begin{array}{l}D \\
E D \\
M D\end{array}$ & $\begin{array}{l}\mathrm{Fr} \\
\mathrm{Fr} \\
\mathrm{Fr}\end{array}$ & $\begin{array}{l}L P / L P \\
L P / L P \\
P / P\end{array}$ \\
\hline
\end{tabular}

(1) Textura: AF (areia franca), F (franco), FA (franco-arenoso), FAA (franco-argilo-arenoso), A (argila), MA (muito argiloso). ${ }^{(2)}$ Consistência Seca: LD (ligeiramente duro), MD (muito duro), ED (extremamente duro); Úmida: MFr (muito friável), Fr (friável), Fr/F (friável a firme), F (firme), F/MF (firme a muito firme), MF (muito firme); Molhada: NP/NP (não-plástico e não pegajoso) (NP/LP (não-plástico e ligeiramente pegajoso), LP/LP (ligeiramente plástico e ligeiramente pegajoso), P/LP (plástico e ligeiramente pegajoso), P/P (plástico e pegajoso), MP/MP (muito plástico e muito pegajoso). (3) Não determinado.

$1 P A_{0}$ e $1 P A_{1}$ apresentaram fração areia superior a $50 \%$ até $50 \mathrm{~cm}$ de profundi dade, decrescendo a partir daí. Para o perfil $2 \mathrm{PA}_{8}$, foram verificados valores maiores que $70 \%$ de material arenoso, enquanto as frações silte e argila variaram no máximo de 10 a $20 \%$ ao longo do perfil. A variação irregular da textura com a profundidade dos perfis deveu-se à granul ometria dos materiais de origem eao processo desistematização. Esse comportamento foi natural, tendo em vista não existir uma pré-sel eção de material do solo para efetuar oaterramento deforma correta, conforme normativa do IBAMA (1990). 
Quadro 2. Características físicas de diferentes horizontes e, ou, camadas, de perfis originais e solos sistematizados (corte e aterro) para o cultivo de arroz

\begin{tabular}{|c|c|c|c|c|c|c|c|c|c|c|}
\hline $\begin{array}{c}\text { Horizonte } \\
\text { e, ou, camada }\end{array}$ & Limite & $\begin{array}{c}\text { Areia } \\
\text { grossa }\end{array}$ & $\begin{array}{l}\text { Areia } \\
\text { fina }\end{array}$ & Silte & Argila & $A D^{(1)}$ & Silte/argila & ds $\mathbf{s}^{(2)}$ & $d p^{(3)}$ & $\mathbf{P} \mathbf{t}^{(4)}$ \\
\hline & $\mathrm{cm}$ & 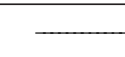 & 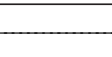 & $\mathrm{g} \mathrm{kg}^{-1}$ & 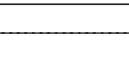 & 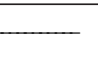 & & \multicolumn{2}{|c|}{$-\mathrm{Mg} \mathrm{m}^{-3}-$} & $\mathrm{dm}^{3} \mathrm{dm}^{-3}$ \\
\hline $\begin{array}{l}A_{1} \\
E \\
\text { Btg }\end{array}$ & $\begin{array}{c}0-40 \\
40-80 \\
80-130\end{array}$ & $\begin{array}{l}99 \\
66 \\
43\end{array}$ & $\begin{array}{l}527 \\
525 \\
354\end{array}$ & $\begin{array}{c}\text { Áre } \\
\text { fil orig } \\
219 \\
263 \\
186\end{array}$ & $\begin{array}{l}1 \\
\text { hal - 1PO } \\
155 \\
146 \\
417\end{array}$ & $\begin{array}{c}---(5) \\
10 \\
261\end{array}$ & $\begin{array}{l}1,40 \\
1,80 \\
0,45\end{array}$ & $\begin{array}{l}1,70 \\
1,74 \\
1,50\end{array}$ & $\begin{array}{l}2,52 \\
2,53 \\
2,59\end{array}$ & $\begin{array}{l}0,32 \\
0,31 \\
0,42\end{array}$ \\
\hline \multicolumn{11}{|c|}{ Perfil de aterro-1PA。 } \\
\hline 1 & $0-10$ & 125 & 507 & 186 & 182 & 121 & 1,02 & -- & -- & -- \\
\hline${ }_{A_{1} b}$ & $\begin{array}{l}10-19 / 21 \\
19 / 21-27 / 35\end{array}$ & $\begin{array}{r}111 \\
94\end{array}$ & $\begin{array}{l}491 \\
505\end{array}$ & $\begin{array}{l}198 \\
209\end{array}$ & $\begin{array}{l}200 \\
192\end{array}$ & $\begin{array}{l}100 \\
121\end{array}$ & $\begin{array}{l}0,99 \\
1,10\end{array}$ & $\begin{array}{l}-- \\
--\end{array}$ & $\begin{array}{l}-- \\
--\end{array}$ & $\begin{array}{l}-- \\
--\end{array}$ \\
\hline $\mathrm{BEb}$ & $27 / 35-58 / 64$ & 90 & 545 & 194 & 171 & 101 & 1,13 & -- & -- & -- \\
\hline Btgfb & 58/64-110+ & 77 & 381 & 136 & 406 & 293 & 0,33 & -- & -- & -- \\
\hline \multicolumn{11}{|c|}{ Perfil de aterro-1PA } \\
\hline I & $0-20$ & 83 & 530 & 199 & 188 & 100 & 1,06 & 1,56 & 2,53 & 0,38 \\
\hline$A_{1} b$ & $20-31$ & 73 & 496 & 214 & 217 & 118 & 0,98 & 1,65 & 2,55 & 0,35 \\
\hline $\mathrm{E} / \mathrm{EBb}$ & $31-62$ & 74 & 572 & 187 & 167 & 57 & 0,12 & 1,71 & 2,57 & 0,33 \\
\hline Btgb & $62-80+$ & 48 & 344 & 161 & 447 & 317 & 0,36 & 1,37 & 2,61 & 0,47 \\
\hline \multicolumn{11}{|c|}{ Perfil de corte - $1 \mathrm{PC}_{0}$} \\
\hline I (Btg) & $0-20$ & 52 & 404 & 148 & 396 & 292 & 0,37 & -- & -- & -- \\
\hline $11^{10(9)}$ & $20-40$ & 54 & 502 & 194 & 300 & 228 & 0,65 & -- & -- & -- \\
\hline III & $40-60$ & 82 & 594 & 86 & 238 & 162 & 0,36 & -- & -- & -- \\
\hline \multicolumn{11}{|c|}{ Perfil de corte - $1 P C_{1}$} \\
\hline Ap & $0-5 / 7$ & 74 & 471 & 259 & 196 & 90 & 1,32 & 1,34 & 2,63 & 0,49 \\
\hline I (Btg) & $5 / 7-20$ & 46 & 264 & 192 & 498 & 286 & 0,38 & 1,73 & 2,64 & 0,34 \\
\hline $\begin{array}{l}\mathrm{II} \\
\mathrm{III}\end{array}$ & $\begin{array}{l}20-40 \\
40-60\end{array}$ & $\begin{array}{l}41 \\
51\end{array}$ & $\begin{array}{l}336 \\
410\end{array}$ & $\begin{array}{l}224 \\
200\end{array}$ & $\begin{array}{l}399 \\
339\end{array}$ & $\begin{array}{l}293 \\
207\end{array}$ & $\begin{array}{l}0,56 \\
0,59\end{array}$ & $\begin{array}{l}1, / 1 \\
1,42\end{array}$ & $\begin{array}{l}2,64 \\
2,63\end{array}$ & $\begin{array}{l}0,35 \\
0,46\end{array}$ \\
\hline \multirow{2}{*}{\multicolumn{11}{|c|}{$\begin{array}{c}\text { Área } 2 \\
\text { Perfil original - 2PO }\end{array}$}} \\
\hline & & & & & & & & & & \\
\hline $\begin{array}{l}\mathrm{A} \\
\mathrm{E}\end{array}$ & $\begin{array}{l}0-25 \\
25-33 / 45\end{array}$ & $\begin{array}{r}87 \\
126\end{array}$ & $\begin{array}{l}527 \\
354\end{array}$ & $\begin{array}{l}1 / 8 \\
419\end{array}$ & $\begin{array}{l}208 \\
101\end{array}$ & $\begin{array}{l}92 \\
10\end{array}$ & $\begin{array}{l}0,16 \\
4.15\end{array}$ & $\begin{array}{l}1,50 \\
1,60\end{array}$ & 2,51 & 0,36 \\
\hline $\mathrm{EB}$ & $33 / 45-70 / 74$ & 71 & 525 & 232 & 172 & 92 & 1,35 & 1,70 & 2,50 & 0,32 \\
\hline Btg & $70 / 74-125$ & 43 & 253 & 351 & 353 & 246 & 0,99 & 1,50 & 2,56 & 0,41 \\
\hline \multicolumn{11}{|c|}{ Perfil de aterro $-2 \mathrm{PA}_{8}$} \\
\hline Ap & $0-22$ & 65 & 562 & 204 & 169 & 81 & 1,20 & 1,64 & 2,50 & 0,34 \\
\hline 11 & $22-54$ & 58 & 679 & 162 & 101 & 91 & 1,60 & 1,50 & 2,51 & 0,40 \\
\hline III & $54-68$ & 54 & 563 & 231 & 152 & 5 & 1,20 & 1,61 & 2,53 & 0,36 \\
\hline IV & $68-100+$ & 87 & 624 & 168 & 121 & 10 & 1,39 & 1,56 & 2,52 & 0,38 \\
\hline \multicolumn{11}{|c|}{ Perfil de corte - $2 \mathrm{PC}_{8}$} \\
\hline$A p$ & $0-11 / 13$ & 85 & 496 & 246 & 173 & 66 & 1,42 & 1,75 & 2,57 & 0,32 \\
\hline $\begin{array}{l}\text { II (EB) } \\
\text { III (Btg) }\end{array}$ & $\begin{array}{l}11 / 13-20 \\
20-60+\end{array}$ & $\begin{array}{l}89 \\
54\end{array}$ & $\begin{array}{l}525 \\
369\end{array}$ & $\begin{array}{l}190 \\
216\end{array}$ & $\begin{array}{l}196 \\
361\end{array}$ & $\begin{array}{r}88 \\
196\end{array}$ & $\begin{array}{l}0,97 \\
0,60\end{array}$ & $\begin{array}{l}1,84 \\
1,64\end{array}$ & $\begin{array}{l}2,61 \\
2,61\end{array}$ & $\begin{array}{l}0,29 \\
0,37\end{array}$ \\
\hline
\end{tabular}

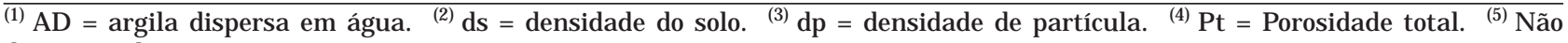
determinado.

Analisando os perfis de corte das áreas 1 e 2, verificaram-se mudanças mais drásticas na granulometria em relação a seus respectivos originais, com maior teor de argila nos horizontes superficiais dos perfis $1 \mathrm{PC}_{0}$ e $1 \mathrm{PC}_{1}$, devido à maior profundidade de corte. Essas mudanças foram relacionadas com a exposição de horizontes subsuperficiais, já referenciadas pela descrição morfológica confirmadas na distribuição granulométrica (Quadro 2). Variações texturais na superfície do solo oriundas do processo de sistematizaçãotambém foram observadas por Unger et al. (1990) e Preve \& Martens (1990).

Os sol os apresentaram, em geral, alta densidade do solo (ds), variando de 1,34 a 1,84 $\mathrm{Mg} \mathrm{m}^{-3}$, com uma média de 1,61 $\mathrm{Mg} \mathrm{m}^{-3}$, enquanto, para a porosidade total (Pt) calculada, foram encontrados valores de 0,28 a $0,47 \mathrm{dm}^{3} \mathrm{dm}^{-3}$, com média de $0,38 \mathrm{dm}^{3} \mathrm{dm}^{-3}$ (Quadro 2). Beltrame \& Louzada (1996), avaliando 
características de Planossolo sob cultivo de arroz, encontraram valores de ds de 1,07 a 1,86 $\mathrm{Mg} \mathrm{m}^{-3} \mathrm{e}$ de Pt de 0,26 a 0,55 $\mathrm{dm}^{3} \mathrm{dm}^{-3}$, engl obando os limites encontrados neste trabalho.

As menores densidades do solo verificadas para as superfícies dos perfis $1 \mathrm{PA}_{1}$ e $1 \mathrm{PC}_{1}$ foram atribuídas ao revolvimento do solo executado durante as práticas de manejo e à incorporação do resíduo orgânico do cultivo anterior. Os val ores mais elevados de densidade do solo e os menores de porosi dade total foram verificados nos perfis decorte, logo abaixo do horizonte Ap, correspondendo às camadas I (Btg) do $1 \mathrm{PC}_{1}$ e II (EB) do $2 \mathrm{PC}_{8}$, independentemente do tempo de sistematização. $\mathbf{E}$ possível que esse estado de compactação seja remanescente dos processos de sistematização e possa ser intensificado com as práticas de manejo do solo (Machado et. al., 1981; Pedrotti et al., 1997). Essas características são compatíveis com o comportamento observado na morfol ogia (Quadro 1).

\section{Propriedades químicas}

Os teores de cátions básicos ( $\mathrm{Ca}, \mathrm{Mg}, \mathrm{K}$ e Na), P e CTC diferenciaram-se nos solos sistematizados comparados aos originais 1PO e2PO, apresentando distribuição irregular em profundidade nos perfis de aterro, $1 \mathrm{PA}_{0}, 1 \mathrm{PA}_{1}$ e $2 \mathrm{PA}_{8}$, e decréscimo em profundidade nos perfis de corte, $1 P C_{0}$ e $1 P C_{1}$ (Quadro 3). Esse comportamento deveu-se à estratificação do material nos perfis de aterro e ao el evado teor de argila na superfície do solo dos perfis de corte, com um decréscimo em profundidade. O perfil $2 \mathrm{PC}_{8}$, em relação ao original $2 \mathrm{PO}$, não apresentou maiores diferenças na distribuição desses elementos, fato atribuído à menor profundidade de corte, que não ocasionou exposição do horizonte Btg.

L ogo após o processo desistematização dos solos, na superfície do perfil $1 P C_{0}$, foram verificados el evados teores de Al trocável e $\mathrm{H}+\mathrm{Al}$, refletindo em um pH ácido, bem como baixos teores de carbono orgânico e fósforo, em decorrência da remoção das camadas superficiais de maior teor de matéria orgânica, com capacidade de complexar oAI (Salet, 1998) edispor demaior reserva em fósforo (Wiethol ter et al., 1998). Além disso, o corte expôs horizontes subsuperficiais, constituídos principalmente por material oriundo do horizonte Btg do original $1 \mathrm{PO}$, com teores deAl trocável e deH + Al muito el evados, em virtude dos al tos teores de argila e baixos teores de carbono orgânico (Gama \& Kiehl, 1995). No entanto, a redução do $\mathrm{Al}$ do $1 \mathrm{PC}_{0}$ para o $1 \mathrm{PC}_{1}$, principal mente na superfície do horizonteAp, deveuse provavel mente à complexação do Al pelo material orgânico incorporado neste horizonte do solo pela cultura do arroz.

Na área 2, os teores deAl trocável verificados no perfil $2 \mathrm{PC}_{8}$ foram um pouco superiores aos do perfil original 2PO, enquanto o carbono orgânico e fósforo foram inferiores. Isso deveu-se à remoção de camadas superficiais e à exposição de material de horizontes subsuperficiais pelo processo de sistematização. No entanto, em relação aos perfis $1 \mathrm{PC}_{0}$ e $1 \mathrm{PC}_{1}$, os teores de Al trocável do perfil $2 \mathrm{PC}_{8}$ foram mais baixos em virtude do menor teor de argila (Quadro 2) encontrado na superfície do solo ou próximo desse, já que a decapagem do solo foi menos profunda, não ocorrendo a exposição do horizonte Btg.

E $m$ relação aos originais $1 \mathrm{PO}$ e $2 \mathrm{PO}$, nos perfis de aterro $1 \mathrm{PA}_{0}, 1 P \mathrm{~A}_{1}$ e $2 \mathrm{PA}_{8}$, foi verificado pequeno aumento nos valores de $\mathrm{Al}$ trocável e $\mathrm{H}+\mathrm{Al}$, atribuído ao incremento de argila decorrente da mistura dos horizontes pelo processo de sistematização. Em síntese, parecehaver mai or risco de toxidez por alumínio às plantas na área de corte, principal mentelogo após a sistematização dos sol os $\left(1 \mathrm{PC}_{0}\right)$, ou seja, no primeiro cultivo.

O comportamento das características químicas, principalmente os elevados teores de Al trocável e baixos teores de carbono orgânico e de fósforo, foi influenciado pela intervenção antrópica, ou seja, exposição de horizontes subsuperficiais, devendo-se ter mais cuidado com a fertilidade dos solos nessas áreas (IRGA, 1996). Preve \& Martens (1990) constataram que, em áreas sistematizadas, por causa da exposição de horizontes subsuperficiais, ocorreram deficiências de $\mathrm{P}, \mathrm{K}$ e Zn, podendo outras deficiências ocorrer em solos com propriedades químicas e físicas diferentes. Esses problemas, de natureza química e física, foram minimizados com a incorporação de resíduos orgânicos (Robins et al., 1997), com o revolvimento e o cultivo nos anos subseqüentes.

\section{Características de compostos de ferro}

Os teores de ferro total (Fet), em todos os solos estudados, podem ser considerados baixos (Figuras 1 e2). Na maioria dos horizontes e camadas dos sol os das duas áreas, os val ores situaram-se em torno de 5 a $20 \mathrm{~g} \mathrm{~kg}^{-1}$, compatíveis com características constatadas em outros sol os hidromórficos si milares (BRASI L, 1973; Melfi et al., 1979). Em ambos os perfis originais (1PO e 2PO), os teores de Fet, Fed e Feo decresceram dos horizontes superficiais para o horizonte $\mathrm{E}$, atingindo os valores máximos nos horizontes Btg.

O valor máximo de Fet foi encontrado na camada ou horizonte III (Btg) do perfil 2PC $8\left(23,6 \mathrm{~g} \mathrm{~kg}^{-1}\right)$, tendo sido valores similares a esses verificados próximos à camada superficial do perfil decorte $1 \mathrm{PC}_{1}$ $\left(19,4 \mathrm{~g} \mathrm{~kg}^{-1}\right)$ ena superfície do $2 \mathrm{PC}_{8}\left(17 \mathrm{~g} \mathrm{~kg}^{-1}\right)$, assim como nos horizontes Btg dos perfis originais da área $1\left(19,5 \mathrm{~g} \mathrm{k}^{-1}\right)$ eárea $2\left(21,3 \mathrm{~g} \mathrm{~kg}^{-1}\right)$. Esses valores evidenciaram ser o Fe originado do mesmo horizonte do solo, já que os teores de ferro em valores maiores mostraram-se associados à presença de maior teor 
Quadro 3. Propriedades químicas de diferentes horizontes e, ou, camadas, de perfis originais e solos sistematizados (corte e aterro) para o cultivo de arroz

\begin{tabular}{|c|c|c|c|c|c|c|c|c|c|c|c|c|c|}
\hline $\begin{array}{l}\text { Horizonte } \\
\text { e, ou, camada }\end{array}$ & $\mathrm{pH} \mathrm{H}_{2} \mathrm{O}$ & $\mathrm{Ca}$ & Mg & K & $\mathrm{Na}$ & $\mathbf{S B}(1)$ & Al & $\mathbf{H}+\mathbf{A l}$ & CTC(2) & $\mathbf{V}^{(3)}$ & Sat. $A I^{(4)}$ & $\mathbf{P}(5)$ & C org ${ }^{(5)}$ \\
\hline & & & & & $-\mathrm{cm}$ & $\mathrm{lckg}_{\mathrm{c}} \mathrm{kg}^{-1}$ & & & & \multicolumn{2}{|c|}{ —— } & \multirow[t]{2}{*}{$\mathrm{mg} \mathrm{kg}^{1}$} & \multirow[t]{2}{*}{$\mathrm{g} \mathrm{kg}^{-1}$} \\
\hline \multirow{2}{*}{\multicolumn{14}{|c|}{$\begin{array}{r}\text { Área } 1 \\
\text { erfil original }\end{array}$}} \\
\hline & & & & & & & & & & & & & \\
\hline $\mathrm{A}_{1}$ & 5,0 & 2,0 & 1,7 & 0,03 & 0,04 & 3,8 & 0,9 & 2,5 & 6,3 & 60 & 19 & 7,6 & 5,9 \\
\hline $\mathrm{E}$ & 5,8 & 2,4 & 1,7 & 0,03 & 0,06 & 4,2 & 0,3 & 0,6 & 4,7 & 89 & 7 & 1,0 & 1,6 \\
\hline Btg & 5,2 & 5,3 & 2,8 & 0,14 & 0,22 & 8,5 & 6,4 & 8,6 & 16,8 & 51 & 43 & 2,9 & 3,7 \\
\hline \multicolumn{14}{|c|}{ Perfil de aterro - 1PA。 } \\
\hline 1 & 4,8 & 1,6 & 1,4 & 0,15 & 0,01 & 3,2 & 1,3 & 4,1 & 7,3 & 44 & 29 & 10 & 5,6 \\
\hline II & 4,8 & 1,3 & 2,6 & 0,07 & 0,02 & 4,0 & 1,7 & 2,2 & 6,2 & 64 & 30 & 4 & 5,4 \\
\hline$A_{1} b$ & 4,9 & 2,5 & 0,5 & 0,07 & 0,02 & 3,1 & 2,3 & 4,4 & 7,5 & 41 & 43 & 3 & 4,1 \\
\hline $\mathrm{BEb}$ & 5,1 & 1,3 & 0,9 & 0,06 & 0,01 & 2,3 & 2,0 & 3,0 & 5,3 & 43 & 46 & 2 & 1,8 \\
\hline Btgfb & 5,0 & 1,7 & 2,2 & 0,25 & 0,07 & 4,2 & 7,9 & 10,2 & 18,6 & 23 & 65 & 2 & 3,0 \\
\hline \multicolumn{14}{|c|}{ Perfil de aterro- $1 \mathrm{PA}_{1}$} \\
\hline 1 & 4,8 & 2,3 & 1,5 & 0,13 & 0,04 & 4,0 & 1,2 & 4,6 & 8,6 & 46 & 32 & 4,0 & 7,0 \\
\hline$A_{1} b$ & 5,1 & 1,5 & 2,5 & 0,04 & 0,12 & 4,2 & 2,9 & 6,0 & 10,2 & 41 & 41 & 1,0 & 7,1 \\
\hline$E / E B b$ & 5,1 & 3,1 & 0,6 & 0,06 & 0,04 & 3,8 & 2,1 & 3,0 & 6,8 & 56 & 36 & 1,7 & 1,9 \\
\hline Btgfb & 4,9 & 4,7 & 1,5 & 0,16 & 0,19 & 6,6 & 7,3 & 9,3 & 15,9 & 41 & 53 & 2,2 & 3,8 \\
\hline \multicolumn{14}{|c|}{ Perfil de corte-1PCo } \\
\hline I (Btg) & 4,7 & 7,0 & 1,8 & 0,24 & 0,07 & 9,1 & 7,2 & 8,4 & 17,5 & 52 & 44 & 1,0 & 3,3 \\
\hline 11 & 4,9 & 4,8 & 2,3 & 0,19 & 0,05 & 7,3 & 5,9 & 6,8 & 14,1 & 52 & 45 & 1,5 & 2,2 \\
\hline III & 4,8 & 2,0 & 5,1 & 0,21 & 0,05 & 7,4 & 4,4 & 5,5 & 12,9 & 58 & 37 & 1,5 & 1,8 \\
\hline \multicolumn{14}{|c|}{ Perfil de corte - $1 P C_{1}$} \\
\hline Ap & 4,8 & 5,5 & 2,0 & 0,32 & 0,08 & 7,9 & 1,8 & 6,6 & 14,5 & 54 & 19 & 20 & 4,2 \\
\hline I (Btg) & 5,2 & 4,5 & 2,8 & 0,21 & 0,22 & 7,7 & 4,1 & 3,1 & 10,6 & 73 & 35 & 5,3 & 2,6 \\
\hline II & 5,1 & 4,0 & 2,2 & 0,27 & 0,27 & 6,7 & 5,0 & 6,0 & 12,7 & 53 & 43 & 4,4 & 1,7 \\
\hline III & 5,2 & 1,9 & 2,0 & 0,25 & 0,22 & 4,4 & 5,0 & 6,7 & 11,1 & 40 & 58 & 4,4 & 1,4 \\
\hline \multirow{2}{*}{\multicolumn{14}{|c|}{ Área 2}} \\
\hline \multicolumn{13}{|c|}{ Perfil Original 2PO } & \\
\hline$A_{1}$ & 5,5 & 4,5 & 2,9 & 0,07 & 0,08 & 7,6 & 1,0 & 3,3 & 10,9 & 70 & 12 & 4,4 & 7,5 \\
\hline $\mathrm{E}$ & 5,5 & 2,1 & 1,3 & 0,02 & 0,03 & 3,5 & 0,5 & 1,0 & 4,5 & 78 & 13 & 1,0 & 2,3 \\
\hline EB & 5,3 & 1,7 & 2,1 & 0,03 & 0,10 & 3,9 & 1,7 & 2,8 & 6,7 & 58 & 30 & 1,0 & 1,9 \\
\hline Btg & 5,3 & 8,0 & 3,2 & 0,06 & 0,43 & 11,7 & 4,5 & 6,8 & 18,5 & 63 & 28 & 4,1 & 3,1 \\
\hline \multicolumn{14}{|c|}{ Perfil de aterro- $2 \mathrm{PA}_{8}$} \\
\hline Ap & 5,1 & 3,4 & 1,9 & 0,25 & 0,06 & 5,6 & 1,0 & 2,6 & 8,2 & 68 & 28 & 6,2 & 4,1 \\
\hline 11 & 6,3 & 3,2 & 2,4 & 0,14 & 0,04 & 5,8 & 0,1 & 0,6 & 6,4 & 91 & 2 & 2,9 & 2,4 \\
\hline III & 6,3 & 4,1 & 2,1 & 0,11 & 0,04 & 6,4 & 0,2 & 0,8 & 7,2 & 89 & 3 & 1,8 & 2,0 \\
\hline IV & 6,2 & 3,5 & 1,6 & 0,10 & 0,06 & 5,3 & 0,1 & 0,5 & 5,8 & 91 & 2 & 2,9 & 1,6 \\
\hline \multicolumn{14}{|c|}{ Perfil de corte - $2 \mathrm{PC}_{8}$} \\
\hline Ap & 5,1 & & 2,1 & 0,27 & 0,05 & & 1,3 & & 8,2 & 39 & 21 & 2,9 & 4,6 \\
\hline$I I(E B)$ & 5,4 & 3,5 & 1,6 & 0,18 & 0,13 & 5,4 & 2,0 & 3,0 & 8,4 & 64 & 27 & 3,7 & 1,4 \\
\hline III (Btg) & 5,2 & 4,0 & 3,9 & 0,25 & 0,26 & 8,4 & 7,3 & 8,8 & 17,2 & 49 & 47 & 4,8 & 2,3 \\
\hline
\end{tabular}

(1) SB = soma de bases. ${ }^{(2)}$ CTC = Capacidade de troca de cátion. ${ }^{(3)} \mathrm{V}=$ Saturação por bases. ${ }^{(4)}$ Sat. Al = Saturação por alumínio. (5) $\mathrm{P}=$ Fósforo. ${ }^{\left({ }^{6}\right)} \mathrm{C}$ org = carbono orgânico.

de argila no horizonte $B$ textural, resultante do processo de eluviação/iluviação (Melfi et al., 1979). A destruição de argilas nos horizontes superficiais por ferrólise (Brinkmann, 1969/1970) podetambém ter contribuído para explicar a distribuição diferencial deFenos horizontes dos sol os estudados. A sistematização do terreno, com a exposição de horizontes Btg dos Planossolos na superfície ou próximos à superfície de corte, influiu na distribuição dos diferentes compostos deferro nos perfis estudados. 
Perfil original (1PO)
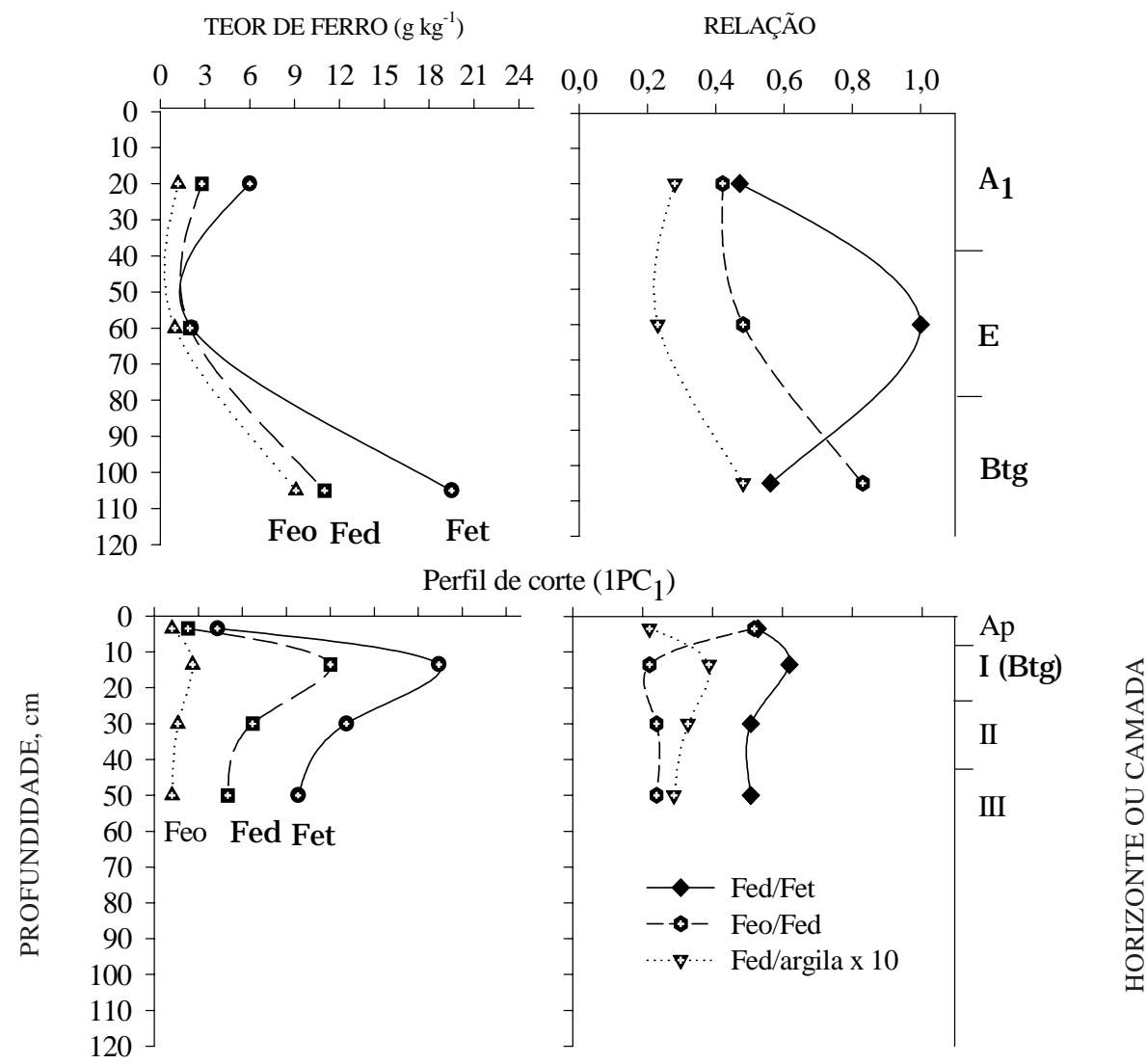

Perfil de aterro $\left(1 \mathrm{PA}_{1}\right)$

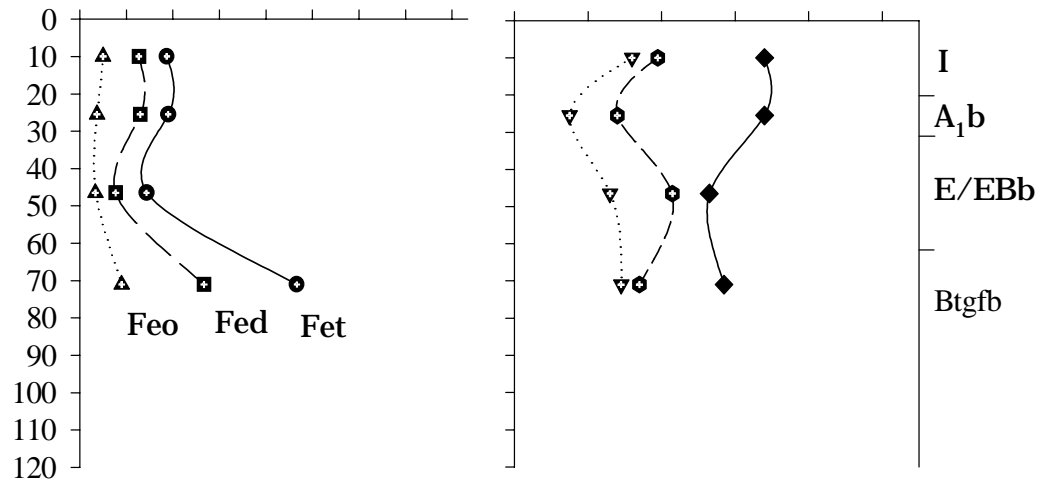

Figura 1. Distribuição dos teores de Fe oxalato (Feo), Fe ditionito (Fed), Fe total (Fet) e as relações Feo/Fed, Fed/Fet e Fed/argila para os perfis: original, de corte e de aterro na área sistematizada há um ano para cultivo de arroz.

Na área 1, pela relação Fed/Fet, foi verificada maior proporção de óxidos livres (Fed) na superfície dos perfis $1 \mathrm{PA}_{1}$ e $1 \mathrm{PC}_{1}$ em relação ao perfil do solo original 1PO. A relação Feo/Fed indicou maior proporção de ferro mal cristalizado, passível de ser mais rapidamente solubilizado em condições de redução do solo (Kämpf, 1987), somente para a superfície do perfil $1 P C_{1}$. Na área 2 , a relação Fed/
Fet nos perfis $2 \mathrm{PA}_{8}$ e $2 \mathrm{PC}_{8}$ foi inferior à do perfil $2 \mathrm{PO}$, evidenciando, nos primeiros, a ocorrência de mais ferro na estrutura dos argilominerais passível deser intemperizado. J á a relação Feo/Fed manteve-sealta ao longo do perfil $2 \mathrm{PA}_{8}$, com valor máximo de 0,88 na superfície. I sso indica alta proporção de compostos de ferro mal cristalizados e possivel mente de $\mathrm{Fe}^{2+}$ decorrente do processo de umedecimento e 
Perfil original (2PO)

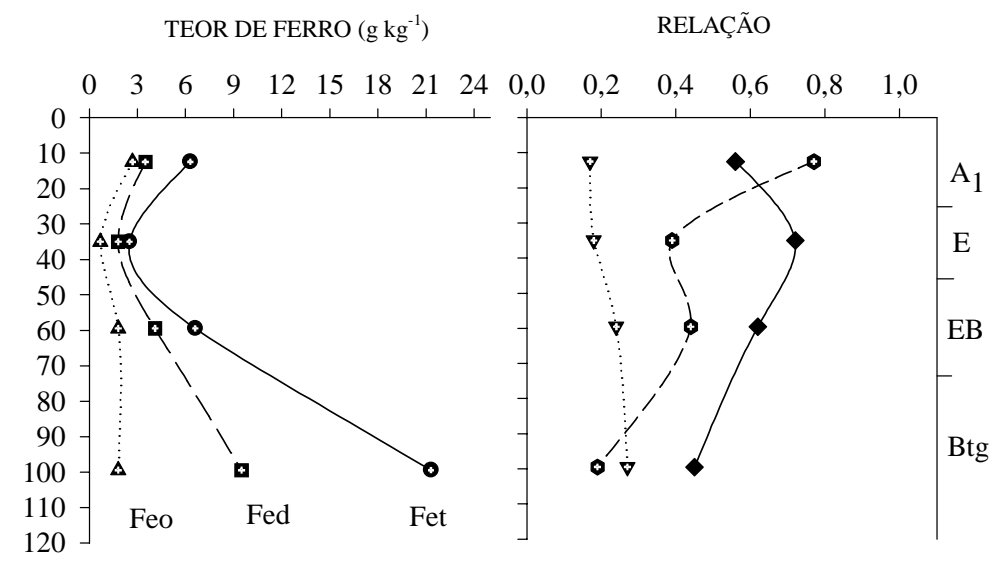

Perfil de corte $\left(2 \mathrm{PC}_{8}\right)$

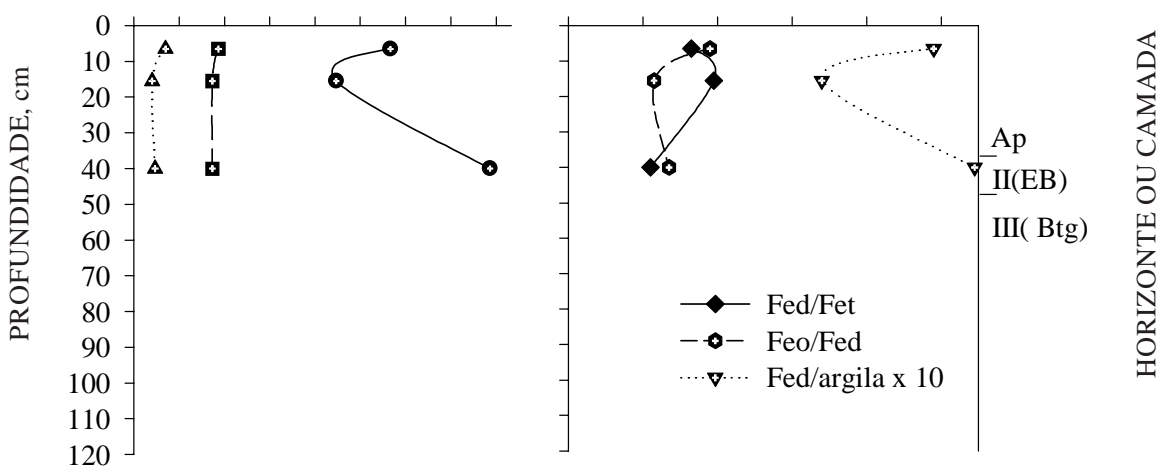

Perfil de aterro $\left(2 \mathrm{PA}_{8}\right)$

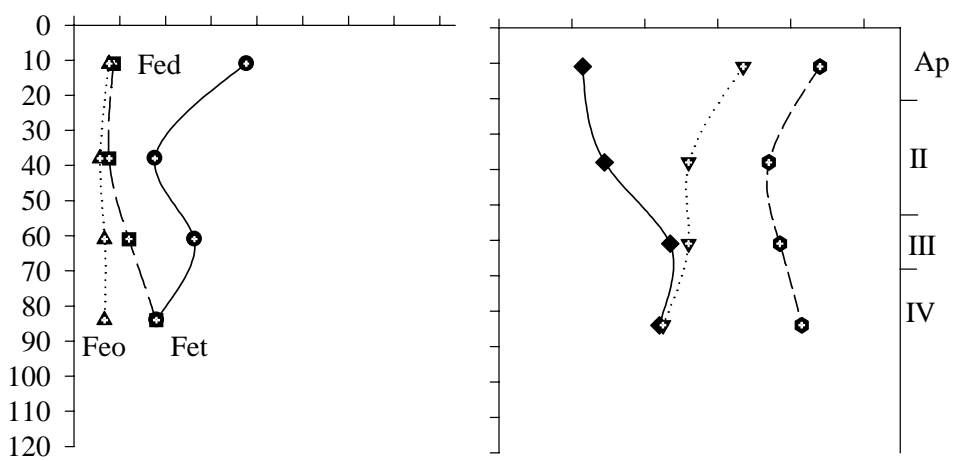

Figura 2. Distribuição dos teores de Fe oxalato (Feo), Fe ditionito (Fed), Fe total (Fet) e as relações F eo/Fed, Fed/F et e Fed/argila para os perfis: original, de corte e de aterro na área sistematizada há oito anos para cultivo de arroz.

secagem imposto pela irrigação, podendo acarretar problemas de fitotoxidez em plantas de arroz (Ponnamperuma, 1972; Fageria, 1989).

Nas áreas 1e2, os teores deferro total (Fet) foram superiores aos de al umínio total (Alt), mas não houve maiores diferenças entre os perfis sistematizados e seu respectivo original. Isso mostra uma ligeira superioridade das formas ativas do ferro sobre as formas ativas do alumínio (Moura et al., 1995). Os teores deAl (Alt, Ald eAlo) (Quadro 4) variaram em razão das soluções empregadas e do tipo de solo (original ou sistematizado) da áreas 1 e 2 . As soluções de DCB (Ald) e oxalato (Alo) extraem polímeros ou formas de baixa cristalinidade ou, ainda, alumínio contido nos óxidos de ferro. Assim, os teores deAlo eAld ea relaçãoAlo/Ald representam 
diversas formas de Al com alta atividade nos solos, correspondentes a polímeros dealumínio, superfícies intemperizadas de argilominerais, sulfatos de alumínio e hidróxi-Al silicatos amorfos (Kämpf et al., 1996).

A distribuição dos teores de Alt, Ald e Alo nos perfis originais decresceu dos horizontes superficiais para o horizonteE eaumentou para o Btg. Como os teores de ferro anteriormente relatados, os teores de Alt, Ald e Alo foram máximos nos horizontes e, ou, camadas (áreas 1 e 2) com maior teor de argila (Quadro 2), graças à co-migração doalumínio eargila (Gianluppi, 1979), ocorrida antes do processo de sistematização.

\section{CONCLUSÕES}

1. Nas áreas de corte, em Planossol os sistematizados, observaram-se as maiores alterações nos horizontes superficiais em relação aos perfis originais, apresentando maiores teores de argila e de Al trocável e menores de matéria orgânica e fósforo disponível.

2. Com o intenso tráfego de máquinas, a sistematização aumentou a densidade do solo e diminuiu a porosidade total, sendo essas propriedades rapidamente reconstituídas pelo preparo do sol o e incorporação de resíduos da cultura do arroz.

Quadro 4. Teores e relação das formas de alumínio em diferentes horizontes e, ou, camadas, de perfis originais e solos sistematizados (corte e aterro) para o cultivo de arroz

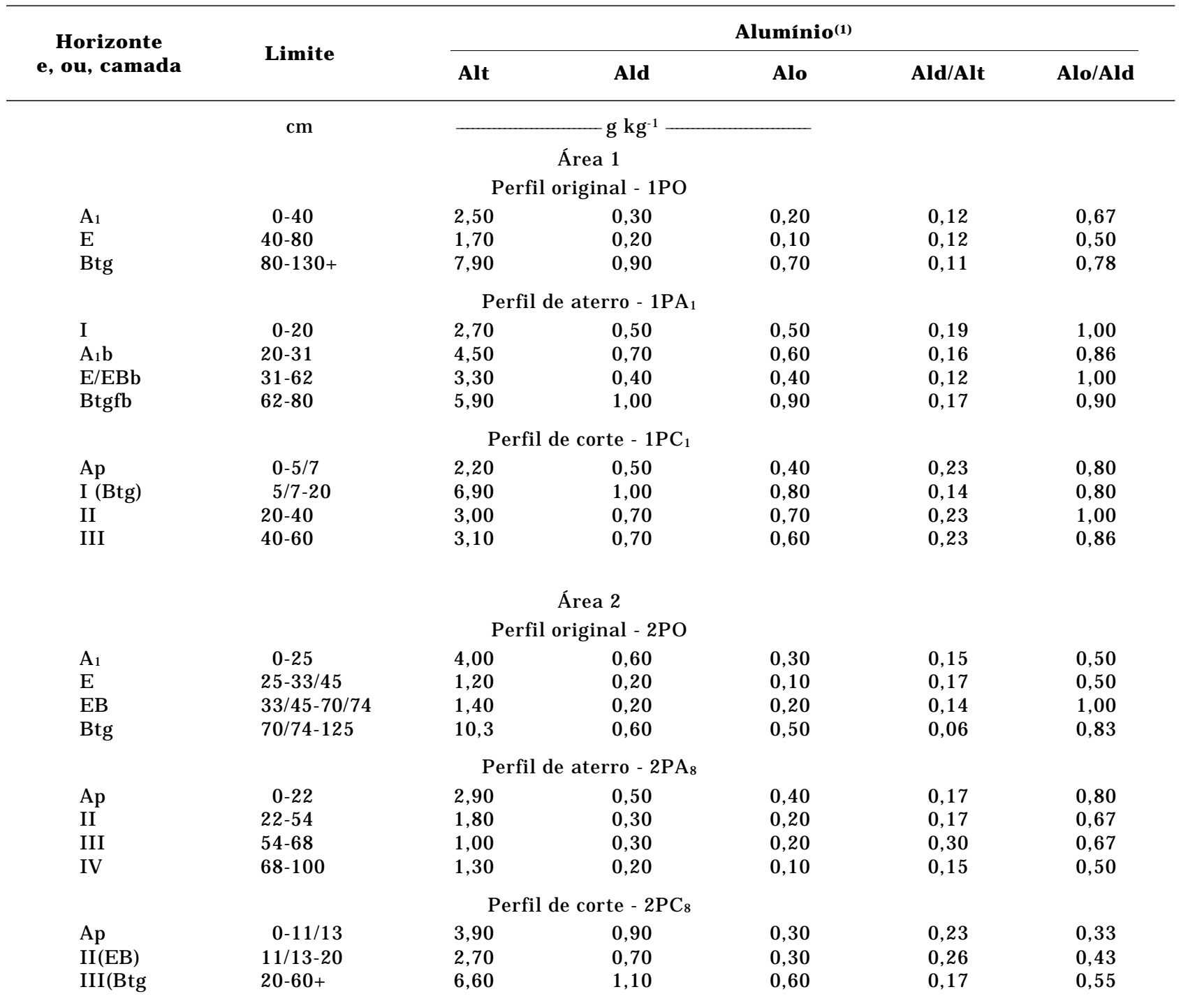

(1) Alt = Alumínio total (extrator $\mathrm{HCl} 6 \mathrm{~mol} \mathrm{~L}^{-1}$ ), Ald = Óxidos de alumínio livres (extrator DCB), Alo = Alumínio mal cristalizado (extrator oxalato de amônio pH 3,0). 
3. A exposição de horizontes Btg nas áreas de corte, com elevado teor em argila ebaixos de matéria orgânica e fósforo, originou condições físicas e químicas desfavoráveis ao crescimento das plantas nos primeiros anos após a sistematização.

4. Nos Planossolos, os teores de Fet, Fed e Feo decresceram dos horizontes superficiais para o horizonte E ecresceram deste para o horizonteBtg, mais argiloso.

5. A sistematização do terreno, com exposição de horizontes subsuperficiais nas áreas de corte e a mistura de materiais nas áreas de aterro, alterou a distribuição dos teores de Fet, Fed e Feo nos perfis.

\section{LITE RATURA CITADA}

ANBUMOZHI, V.; YAMAJ I, E. \& TABUCHI, T. Rice crop growth and yield as influenced by changes in ponding water depth, water regime and fertigation level. Agric. Water Manag., 37:241-253, 1998.

BELTRAME, L.F.S. \& LOUZADA, J.A.S. Caracterização físicohídrica dos solos formadores da várzea arrozeira do Rio Grande do Sul. Porto Alegre, Instituto de Pesquisas Hidráulicas, Universidade Federal do Rio Grande do Sul, 1996. 31p.

BLAKE, G.R. \& HARTGE, K.H. Bulk density. In: KLUTE, A., ed. Methods of soil analysis: Physical and mineralogical methods. Madison, American Society of Agronomy, 1986. p.363-375.

BRASI L. Ministério da Agricultura Departamento Nacional de Pesquisa Agropecuária divisão de Pesquisa Pedológica. Levantamento de reconhecimento dos solos do estado do Rio Grande do Sul. Recife, 1973. 431p. (Bol etim técnico, 30)

BRINKMAN, R. Ferrolysis, a hydromorphic soil forming process. Geoderma, 3:199-206, 1969/1970.

CAMARGO, M.N.; KLAMT, E. \& KAUFMAN, J. Classificação de solos usada em levantamento pedológico no Brasil. Campinas, Sociedade Brasileira de Ciência do Solo, 1987. $24 p$.

DICK, D.P. \& KÄMPF, N. Comparação da extração de ferro com $\mathrm{HCl} 6 \mathrm{~N}, \mathrm{H}_{2} \mathrm{SO}_{4}$ 1:1 e ditionito-citrato-bicarbonato de sódio em horizontes B-latossólicos. R. Bras. Ci. Solo, 12: 185188, 1988.

EMPRESA BRASILEIRA DE PESQUISA AGROPECUÁRIA EMBRAPA. Arroz irrigado: recomendações técnicas da pesquisa para o sul do Brasil. Pelotas, Empresa Brasileira de Pesquisa Agropecuária/Instituto Riograndense doArroz/ E mpresa de Pesquisa Agropecuária e Difusão deTecnol ogia de Santa Catarina, 1999b. 124p.

EMPRESA BRASILEIRA DE PESQUISA AGROPECUÁRIA EMBRAPA. Manual de métodos de análise do solo, $2^{a}$. ed. Rio de Janeiro, Empresa Brasileira de Pesquisa Agropecuária, 1997. 212p.

EMPRESA BRASILEIRA DE PESQUISA AGROPECUÁRIA EMBRAPA. Recomendações técnicas para o cultivo do arroz irrigado. Brasília, Empresa Brasileira de Pesquisa Agropecuária/E mpresa de Pesquisa Agropecuária e Difusão de Tecnologia de Santa Catarina, 1992. 79p.
EMPRESA BRASILEIRA DE PESQUISA AGROPECUÁRIA EMBRAPA. Sistema brasileiro de classificação de solo. Rio de J aneiro, Empresa Brasileira de Pesquisa Agropecuária, 1999a. 412p.

FAGERIA, N.K. Química de solos de várzea In: SIMPÓSIO AVANÇADO DE SOLOS E NUTRIÇÃO DE PLANTAS, 2., Piracicaba, 1989. Anais. Piracicaba, Escola Superior de Agronomia Luiz de Queiroz, 1989. p.93-114.

FAO. Soil map of world. Roma, World Reference Base for Soil Resources, 1998. 91p.

GAMA, J.R.N.F. \& KIEHL, J. O alumínio trocável de um solo Podzólico Vermel ho-Amarelo do Acre e sua absorção pelas plantas. In: CONGRESSO BRASI LEIRO DE CIÊNCIA DO SOLO, 25., Viçosa, 1995. Anais. Viçosa, Sociedade Brasileira de Ciência do Solo, 1995. p.1064-1066.

GIANLUPPI, D. Morfologia e gênese de solos do Litoral-Norte do Estado do Rio Grande do Sul. PortoAlegre, Universidade Federal do Rio Grande do Sul, 1979. 106p. (Tese de Mestrado)

HEILMAN, M.D. \& THOMAS, J.R. Land leveling can adversely affect soil fertility. J. Soil Water Conserv., 16:71-72, 1961.

INSTITUTO BRASILEIRO DE MEIO AMBIENTE - IBAMA. Manual de recuperação de áreas degradadas pela mineração: técnicas de revegetação. Brasília, Instituto Brasileiro de Meio Ambiente, 1990. 96p.

INSTITUTO RIOGRANDESE DO ARROZ - IRGA. ArroZ irrigado: recomendações técnicas da pesquisa para o sul do Brasil. 3.ed. Cachoeirinha, Instituto Riograndense do Arroz, 1996. 88p.

KÄMPF, N. Ferro em solos inundados. In: REUNIÃO SOBRE FERRO EM SOLOS INUNDADOS, 1., Goiânia, 1987. Anais. Goiânia, Empresa Brasileira de Pesquisa Agropecuária, 1987. p.35-71.

KÄMPF, N.; SCHNEIDER, P. \& GIASSON, E. Propriedades, pedogênese e classificação de solos construídos em áreas de mineração na bacia carbonífera do Baixo J acuí, RS. R. Bras. Ci. Solo, 21:79-88, 1997.

KÄMPF, N.; SCHNEIDER, P.; BOHNEN, H.; GIASSON, E. \& BISSANI, C.A. Solos construídos em áreas de mineração da Bacia Carbonífera do Baixo J acuí, no Rio Grande do Sul. Porto Alegre, Relatório PADCT/CIAMB-CNPq, 1996.

KLAMT, E.; DALMOLIN, R.S.D. \& CABRAL, D.R. Solos do município de São J oão do Polêsine: Características, classificação, distribuição geográfica eaptidão deuso. Santa Maria, Universidade Federal de Santa Maria, 1997. 77p.

LEMOS, R.C. \& SANTOS, R.D. Manual de descrição e col eta de solos a campo. 3.ed. Campinas, Sociedade Brasileira de Ciência do Solo, 1996. 83p.

MACHADO, J.A.; SOUZA, P.D.M. \& BRUM, A.C.R. Efeito de anos de cultivo convencional em propriedades físicas do solo. R. Bras. Ci. Solo, 5:187-189, 1981.

McKEAGUE,J .A.\& DAY,J.H. Dithioniteand oxalate-extractable Fe end $\mathrm{Al}$ as aids in differentiating various classes of soils. Can. J. Soil Sci., 46:13-22, 1966. 
MEHRA, O.P. \& J ACKSON, M.L. I ron oxide removal from soils and clays bay dithionite-citrate system buffered with sodium bicarbonate. In: NATIONAL CONFERENCE ON CLAY MINERALS, 7., Washington, 1958. Proceedings, 1960. p.317-327.

MELFI,A.J .; PEDRO, G. \& VOLKOFF, B. Natureza edistribuição dos compostos ferríferos nos solos do Brasil. R. Bras. Ci. Solo, 3:47-54, 1979.

MOURA, G.F.; LIMA, C.C.; RUIZ, H.A. \& MENDONÇA, E.S. Contribuição da matéria orgânica e de formas extraídas pelo DCB e oxalato na superfície de três solos de Minas Gerais. In: CONGRESSO BRASILEIRO DE CIÊNCIA DO SOLO, 25., Viçosa, 1995. Anais. Viçosa, SociedadeBrasileira de Ciência do Solo, 1995. p.223-225.

PARFITT,J .M.B.; SILVA, C.A.S. \& PETRINI ,J .A. Sistematização de sol os de várzea. In: GOMES, A.S. \& PAULETTO, E.A., eds. Manejo de sol o e da água em áreas de várzea. Pel otas, Empresa Brasileira de Pesquisa Agropecuária, 1999. 201p.

PEDROTTI, A.; VAHL, L.C. \& PAULETTO, E.A. Níveis de compactação do Planossolo e o desenvolvimento radicular de algumas culturas. In: REUNIÃO BRASILEIRA DE MANEJ O E CONSERVAÇÃO DO SOLO E DA ÁGUA, 12., Fortaleza, 1997. Anais Fortaleza, Sociedade Brasileira de Ciência do Sol o/U niversidade Federal do Ceará, 1997. p.8090.

PONNAMPERUMA, F.N. The chemistry of submerged soils. Adv. Agron., 2:429-96, 1972.
PREVE, R.E. \& MARTENS, D.C. Potential effect of land-leveling on soil fertility in a Brazilian rice soil. Plant Soil, 121:148150,1990

ROBBINS, C.W.; MACKEY, B.E. \& FREEBORN, L.L. I mproving exposed subsoils with fertilizers and crop rotations. Soil Sci. Soc. Am. J., 61:1221-1225. 1997.

SALET, R.L. Toxidez dealumínio nosistema plantio direto. Porto Alegre: Universidade Federal do Rio Grande do Sul, 1998. 109p. (Tese Doutorado)

TEDESCO, M.J .; GIANELLO, C.; BISSANI C.A.; VOLKWEISS, S.J. \& BOHNEN, H. Análise de solo, plantas e outros materiais. Porto Alegre, Universidade Federal do Rio Grande do Sul, 1995. 174p. (Boletim Técnico, 5)

THOMAS, J.R.; HEILMAN, M.D. \& LYLES, L. Predicting nitrogen fertilizer requirements after land leveling. Agron. J., 66:371-374. 1974.

UNGER, P.W.; FULTON, L.J . \& J ONES, O.R. Land-leveling effects on soil texture, organic matter content, and aggregate stability. J. Soil Water Conserv., 45:412-415. 1990.

WIETHÖLTER, S.; BEN, J R.; KOCHHANN, R.A. \& POTTKER, D. Fósforo e potássio no sistema plantio direto. In: NUERNBERG, N.J., ed. Conceitos e fundamentos de sistema plantio direto. Lages, Núcleo Regional Sul da Sociedade Brasileira de Ciência do Solo. 1998. 160p. 